\title{
Identifying the Factors that Influence Change in SEBD Using Logistic Regression Analysis
}

\author{
Liberato Camilleri ${ }^{1, *} \&$ Carmel Cefai ${ }^{2}$ \\ ${ }^{1}$ Department of Statistics and Operations Research, University of Malta, Malta \\ ${ }^{2}$ Department of Psychology, University of Malta, Malta \\ *Corresponding author: Department of Statistics and Operations Research, University of Malta, Malta \\ Tel: 356-23-403-069. E-mail: liberato.camilleri@um.edu.mt
}

Received: March 8, 2013

Accepted: July 30, 2013

Online Published: August 19, 2013

doi:10.5430/wje.v3n4p96

URL: http://dx.doi.org/10.5430/wje.v3n4p96

\begin{abstract}
Multiple linear regression and ANOVA models are widely used in applications since they provide effective statistical tools for assessing the relationship between a continuous dependent variable and several predictors. However these models rely heavily on linearity and normality assumptions and they do not accommodate categorical dependent variables. The seminal contribution of John Nelder and Robert Wedderburn (1972) introduced the concept of Generalized Linear Models. GLMs overcome the limitations of Normal regression models and accommodate any distribution which is a member of the exponential family. Moreover, these models relate the dependent variable to the linear predictor (non-random component) through any invertible link function. Logistic regression models are GLMs that accommodate categorical dependent variables. They assume a Binomial distribution and Logit canonical link function. The iteratively re-weighted least squares algorithm using the Fisher scoring technique is employed to maximize the log-likelihood function in GLMs and estimate the model parameters. In this paper, Logistic regression analysis was used to identify the dominant factors that influence change in social, emotional and behaviour difficulties (SEBD) of Maltese children. The study comprised 486 pupils whose SEBD was assessed by both teachers and parents using the Strengths and Difficulties Questionnaire (Goodman 1997) when the children were aged 6 and 9 years old.
\end{abstract}

Keywords: logistic regression analysis; maximum likelihood estimation; SEBD; risk factors

\section{Introduction}

There is increasing concern about the increasing incidence of social, emotional and behaviour difficulties (SEBD) in children and young people. About $20 \%$ of school children experience such difficulties such as ADHD, behaviour problems, anxiety and depression, during the course of any given year and may need the use of mental health services (Centre for Disease Control and Prevention, 2013). In a national study with about $10 \%$ of the school population in Malta, Cefai, Cooper and Camilleri (2008) found that $9.8 \%$ of school children manifested SEBD, such as emotional problems, hyperactivity, conduct problems and problems with peer relationships at a significant level. SEBD in school have implications both for the teachers and peers concerned as well as for the students themselves. In an international study carried out by the OECD (2009) on teacher effectiveness, it was found that on average teachers spent $15 \%$ of teaching and learning time on trying to resolve behaviour difficulties. Teachers also see such difficulties as the main challenge to inclusive education in their classroom (McBeath et al, 2006) and often prefer students with other types of special educational needs (Avramadis and Norwich, 2002; Kalambouka et al., 2007). On the other hand, students with SEBD frequently complain of feeling rejected and treated unfairly by teachers, unsupported in their needs, and excluded from the academic and social aspects of school life (Cefai and Cooper, 2011). They are the most vulnerable students to school failure and premature school leaving, social exclusion, substance use, delinquency and mental health problems (Cole, Daniel and Visser, 2005; Colman et al. 2009).

One of the main issues in preventing and responding effectively to SEBD is to identify the main causes underlying such behaviour. Earlier models, such as the biomedical model, tended to construe the problem as residing within the child, namely the result of biological, psychological or personality problems. On the other hand, more recent 
sociological models, tended to put the blame more on the context, underlining how the context itself in most instances leads to the creation of such difficulties (Cooper and Jacobs, 2011). Such either/or perspectives, however, do not do justice to the complexity of SEBD. An adequate understanding of these difficulties needs to consider the various factors and systems influencing children's development and behaviour. SEBD are a multifaceted issue, resulting from biological, psychological, social and educational influences and an adequate understanding prevention and management of this phenomenon needs to take these into consideration (Cooper and Jacobs, 2011). A biopsychosocial perspective (Cooper and Jacobs, 2011) underlines the need to examine how these influences residing in the various systems in the child's world, including the individual child himself/herself, home, peers, school, and community, interact and contribute to the development of SEBD, and consequently to their prevention and remediation.

This study sought to provide an understanding of SEBD within such a biopsychosocial perspective, seeking to identify the individual, school, home and community risk factors in SEBD. More specifically it examines the various risk factors which predict an increase in SEBD as young children move from the first year in the primary school to the junior primary school (Year 4).

\section{Methodology}

\subsection{Sampling Technique}

To measure change in SEBD, a sample of 486 pupils were selected randomly from 65 state and non-state primary schools in Malta to ensure a good geographical representation. The sample, which guaranteed a maximum margin of error of $4.22 \%$ at the $95 \%$ degree of confidence, comprised 232 male and 254 female pupils and the number of students selected from each school was proportional to the school size.

\subsection{Instrument to Measure Change in SEBD}

The Maltese version of the Strengths and Difficulties Questionnaire was used as a measure of the pupils' social, emotional and behaviour difficulties (Cefai, Cooper and Camilleri, 2008). It is a brief questionnaire which has been used by many researchers as a screening tool to measure social, emotional and behaviour difficulties, and identifies the prevalence of mental health difficulties among children and young people. It comprises four difficulty subscales, measuring emotional symptoms, hyperactivity, conduct problems and peer difficulties. Each subscale is measured using five items rated on a 3-point scale such that the score for each subscale ranges from 0 to 10 . The total difficulty (SEBD) score is generated by summing the scores of the four subscales and ranges from 0 to 40, where the larger the score the higher the likelihood of SEBD. The parents and classroom teachers of the selected pupils were asked to complete the Strengths and Difficulties Questionnaire when the child was 6 years old (Year 1) and repeated the task three years later when the child was 9 years old (Year 4). Two SEBD scores were generated for each child; one assessing the child's social, emotional and behaviour difficulties at the age of 6 years and the other at the age of 9 years.

\subsection{Measures and Covariates}

To identify the factors that predict change in SEBD, the selected pupils their parents and their Year 4 classroom teachers were asked to provide other information related to individual pupils and to the class, school and home environments. Information about individual variables was extracted from teachers' and pupils' questionnaires; the parents' questionnaires provided information about home and community variables, while the teachers' questionnaire provided information about the class and school variables. Most of the variables were assessed on a 3-point ordinal scale (very good, average, poor; always, sometimes, never; frequently, occasionally, rarely).

The teacher questionnaire was divided into three sections, namely a section on the individual pupil being assessed (individual characteristics related to learning, relationships and behaviour), a section on their classroom such as classroom management, pupils' collaboration and relationships, and teacher training, and a section on the whole school such as pupils' behaviour, support and bullying, staff teamwork and collegiality, and school-home relationship.

The parent questionnaire also included three sections, namely one section on demographic variables (family size and structure, parental occupation and education, home language and region), another on the child being assessed (individual characteristics related to relationships with family members and parenting), and another section on the family and community, such as family cohesion and dynamics and community safety and support.

The pupil questionnaire asked questions about the pupil's learning and behaviour at school, relationships with teacher, peers and friends, sources of support at school and at home, relationships with parents, siblings and friends, 
and participation in local organisations. The teacher, parent and pupil questionnaires were all self-administered by the participants, but in the case of some pupils the questionnaire was read to them by a research assistant and the pupils ticked the appropriate boxes for each statement.

\section{Results}

Figure 1 shows that parents tend to provide higher SEBD scores for their children than teachers; however, both teachers and parents agree that SEBD increases with age. Moreover, the increment in the mean SEBD scores was significant for teacher's evaluation but not for parent's assessment. Figure 2 shows that for both teacher's and parent's evaluations there exists a positive relationship between the SEBD scores of children at age 6 and 9 years. This implies that children with high SEBD scores in Year 1 tend to retain their high scores in Year 4 and vice versa; however, it is also evident that a number of children experienced a considerable change in their SEBD; some displaying an improvement and others exhibiting deterioration in their social, emotional and behaviour difficulties.
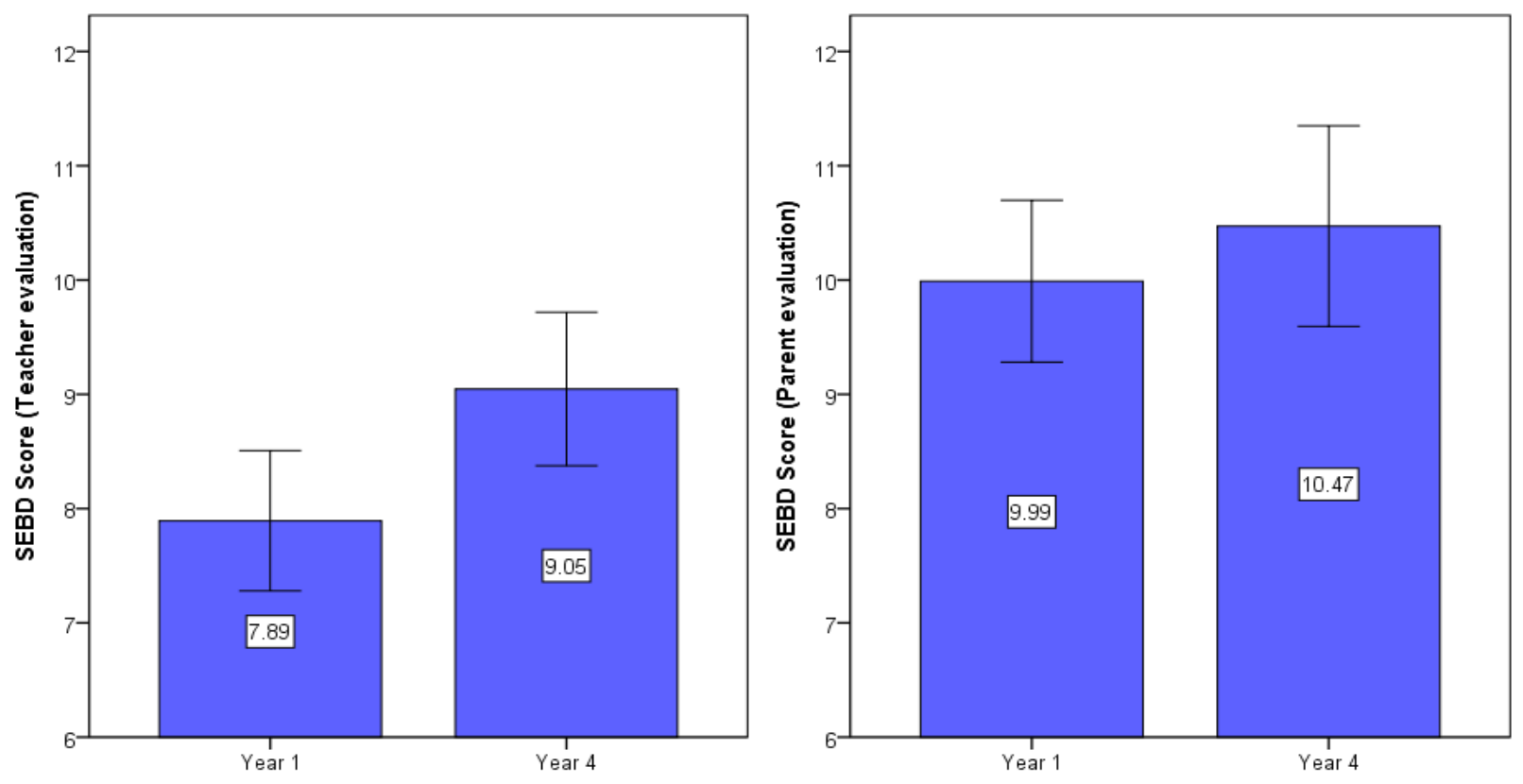

Figure 1: Mean SEBD Scores and 95\% Confidence Interval of 6-Year and 9-Year Old Children 

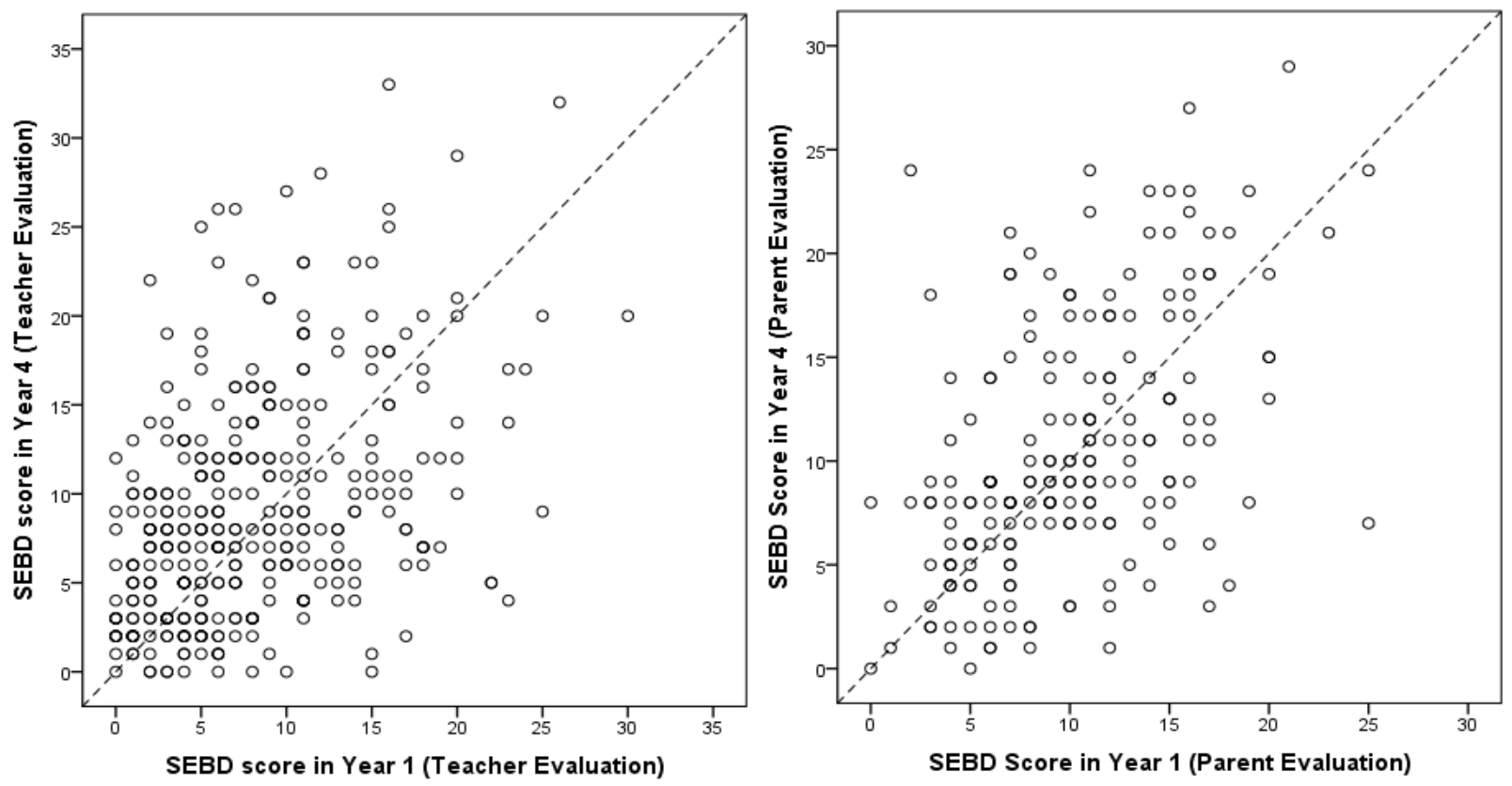

Figure 2: Relationship of SEBD Scores of Children at Age 6 and 9 Years (Teacher and parent evaluations)

\subsection{Factor Analysis}

In addition, Factor analysis was carried out to identify the patterns of the relationships that exist between the two sets of SEBD scores. Using the unrotated factor loadings, the first factor measured the severity of social, emotional, and behaviour difficulties throughout the three-year period and the second factor contrasted between children who displayed improvement in their SEBD scores with those who exhibited deterioration in this period. For both teacher's and parent's evaluations, the first factor explained around 73\% of the total variance in the SEBD scores and the second factor explained about $27 \%$ of the total variance.

\subsection{Logistic Regression Analysis}

A Binomial Logistic model assumes that the dependent variable is dichotomous. To fit this model, the pupils were clustered into two groups depending on whether they experienced an increase or a decrease in their SEBD score. Pupils exhibiting no change in SEBD over the three year period were excluded from the study. Logistic regression analysis was then used to assess the impact of each individual, school and home factor in predicting change in social, emotional and behaviour difficulties and simultaneously identify and rank the strongest predictors (risk factors) that contribute significantly in explaining variation in these responses.

A Binomial Logistic regression model is a probability model that relates a dichotomous response variable to a number of predictors. The model assumes a Binomial distribution and a logit link function. Let $Y$ be a discrete random variable with two possible outcomes

$$
Y= \begin{cases}1 & \text { if pupil experienced an increase in SEBD } \\ 0 & \text { if pupil experienced a decrease in SEBD }\end{cases}
$$

$Y$ has a Binomial distribution with $P(Y=1)=p$. If there are $N$ independent random variables $Y_{1}, Y_{2}, \ldots, Y_{n}$ with $P\left(Y_{i}=1\right)=p_{i}$, then the likelihood function is given by:

$$
L=\prod_{i=1}^{N} p_{i}^{y_{i}}\left(1-p_{i}\right)^{1-y_{i}}=\exp \left[\sum_{i=1}^{N} y_{i} \log \left(\frac{p_{i}}{1-p_{i}}\right)+\sum_{i=1}^{N} \log \left(1-p_{i}\right)\right]
$$

The above distribution belongs to the exponential family, which is given by:

$$
\exp \left[\sum_{i=1}^{N} y_{i} b\left(p_{i}\right)+\sum_{i=1}^{N} c\left(p_{i}\right)+\sum_{i=1}^{N} d\left(y_{i}\right)\right]
$$


$b\left(p_{i}\right)=\log \left(\frac{p_{i}}{1-p_{i}}\right)$ is the natural parameter and $c\left(p_{i}\right)=\log \left(1-p_{i}\right)$ is the cumulant function. The Logistic

regression model that relates the proportion of successes $p_{i}$ to a number of predictors is given by:

$$
\log \left(\frac{p_{i}}{1-p_{i}}\right)=\mathbf{x}_{i}^{\prime} \boldsymbol{\beta}=\eta_{i} \text { and } p_{i}=\frac{\exp \left(\eta_{i}\right)}{1+\exp \left(\eta_{i}\right)}
$$

$\boldsymbol{\beta}$ is a vector of regression parameters, $\mathbf{x}_{i}$ is a vector of explanatory variables and $\eta_{i}$ is the linear predictor. For generalized linear models, maximum likelihood estimates can be obtained by an iterative weighted least squares procedure using the iterative equation

$$
\hat{\boldsymbol{\beta}}=\left(\mathbf{X}^{\prime} \mathbf{W}^{-1} \mathbf{X}\right)^{-1} \mathbf{X}^{\prime} \mathbf{W}^{-1} \mathbf{z}
$$

$\mathbf{X}$ is the design matrix and $\mathbf{W}$ is a diagonal matrix containing iterative weights $w_{i i}$.

$$
w_{i i}=\frac{1}{\operatorname{Var}\left(Y_{i}\right)}\left(\frac{\partial \mu_{i}}{\partial \eta_{i}}\right)^{2}=\frac{\exp \left(\eta_{i}\right)}{\left[1+\exp \left(\eta_{i}\right)\right]^{2}}=p_{i}\left(1-p_{i}\right)
$$

The working variate $\mathbf{z}$ has elements

$$
z_{i}=\eta_{i}+\left(y_{i}-\mu_{i}\right)\left(\frac{\partial \eta_{i}}{\partial \mu_{i}}\right)=\log \left(\frac{p_{i}}{1-p_{i}}\right)+\frac{y_{i}-p_{i}}{p_{i}\left(1-p_{i}\right)}
$$

$\mathbf{W}, \mathbf{z}$ and $\hat{\boldsymbol{\beta}}$ are updated at the each iteration using results of the previous iteration. $\hat{\boldsymbol{\beta}}^{(m)}$ is taken as the maximum likelihood estimate when the difference between the successive approximations $\hat{\boldsymbol{\beta}}^{(m-1)}$ and $\hat{\boldsymbol{\beta}}^{(m)}$ is sufficiently small.

The odds ratio (OR) represents the odds that a pupil will experience an increase in SEBD given a particular exposure, compared to the odds of the outcome occurring in the absence of that exposure. When a logistic regression model is fitted, the regression coefficient $\hat{\beta}_{j}$ is the logarithm of the odds ratio. In other words, the odds ratio and corresponding $95 \%$ confidence interval are:

$$
\begin{gathered}
\text { Odds Ratio }=\exp \left(\hat{\beta}_{j}\right) \\
\text { 95\% Confidence Limits }=\exp \left[\hat{\beta}_{j} \pm 1.96 \text { s. } e\left(\hat{\beta}_{j}\right)\right]
\end{gathered}
$$

\subsection{Findings}

Modelling was carried out mainly through Logistic regression analysis which is used to relate change in SEBD to individual, classroom, school, home and community predictors collectively. Significant predictors were identified and ranked by their contribution in explaining total variance. The Logistic regression model using teachers' evaluations identified fourteen dominant predictors. This fourteen-predictor parsimonious model explains $55.1 \%$ of the total variation in the responses. Table 1 show that eight of these predictors are individual variables mostly related to behaviour, relationships and learning; three are home and community variables, two are whole school variables and the last predictor is a whole classroom variable. According to teachers, the best predictor that identifies changes in the pupil's behaviour difficulties over time is bullying at school. This is followed by the pupil's communication skills, relationship with the teacher, family structure, and gender. The pupils most at risk for developing SEBD would thus be female pupils attending schools where bullying and misbehaviour are prevalent, who have poor communication skills, poor relationship with the teacher and peers, and have few friends. They come from single parent families and have parents 
who are highly stressed. They are also likely to be pupils with poor self-esteem and self-efficacy, experiencing difficulties in their academic difficulties, with poor teacher-parent communication and attending classrooms with poor pupils' participation. Moreover, they do not participate in local organisations.

Table 1: Logistic Regression Analysis Using Teachers' Evaluations

\begin{tabular}{lcccc}
\hline \multicolumn{1}{c}{ Predictor } & Chi square & P-value & Odds ratio & 95\% Conf. Int. \\
\hline Bullying & 9.657 & 0.008 & 3.562 & $(1.883-6.733)$ \\
Communication skills & 9.020 & 0.011 & 3.211 & $(1.727-5.962)$ \\
Teacher-pupils relationship & 5.502 & 0.019 & 2.856 & $(1.620-5.030)$ \\
Family structure & 5.168 & 0.023 & 2.695 & $(1.488-4.879)$ \\
Gender & 4.768 & 0.029 & 2.451 & $(1.418-4.233)$ \\
Relationship with peers & 6.763 & 0.034 & 2.110 & $(1.132-3.936)$ \\
Pupil has friends at school & 4.397 & 0.036 & 2.069 & $(1.209-3.540)$ \\
Pupils' behaviour at school & 4.261 & 0.039 & 1.963 & $(1.094-3.519)$ \\
Pupils' participation in lessons & 6.340 & 0.042 & 1.852 & $(1.032-3.320)$ \\
Parenting stress & 6.293 & 0.043 & 1.803 & $(1.010-2.953)$ \\
Teacher reported self-esteem & 6.247 & 0.044 & 1.762 & $(1.083-2.864)$ \\
Teacher-parent communication & 6.202 & 0.045 & 1.639 & $(1.002-2.680)$ \\
Pupils' academic progress & 6.115 & 0.047 & 1.520 & $(1.005-2.299)$ \\
Participation in organizations & 6.073 & 0.048 & 1.486 & $(1.004-2.199)$ \\
\hline
\end{tabular}

According to teachers, bullied pupils experience social, emotional and behavioural difficulties 3.562 times more often than pupils who are not bullied. Students with poor communication skills are 3.211 times more likely to exhibit SEBD than their peers with good communication skills. Pupils with poor relationship with their teacher exhibit SEBD 2.856 times more often than pupils with good relationships. Students living in single parent family structures are 2.695 times more likely to experience SEBD than pupils living in two-parent family structures. Females are 2.451 times more likely to experience SEBD than males. Pupils with poor relationships with their peers exhibit SEBD symptoms 2.11 times more often than peers who have good relationships. Pupils with no friends at school experience SEBD 2.069 times more often than peers who have friends. Students who misbehave at school exhibit SEBD 1.963 times more often than peers who behave well. Students who do not participate during lessons are 1.852 times more likely exhibit SEBD than peers who participate regularly. Pupils living in families with high levels of parenting stress are 1.803 times more likely to experience SEBD than peers experiencing low levels of parenting stress. Pupils with low self-esteem experience SEBD 1.762 times more often than peers with high self-esteem. Students whose parents have poor communication with teachers are 1.639 times more likely to experience SEBD than peers whose parents communicate well with teachers. Pupils with poor academic progress exhibit SEBD 1.52 times more often than peers making good academic progress. Pupils who do not participating in local organisations are 1.486 times more likely to develop SEBD than more active peers.

The Logistic regression model using parents' evaluations identifies fifteen dominant predictors. This fifteen-predictor parsimonious model explains $62.1 \%$ of the total variation in the responses. Table 2 shows that seven of these predictors are individual variables mostly related to behaviour, relationships and learning; six are home and community variables; one is a whole classroom variable and another a whole school variable. The best discriminant predictor is gender, followed by bullying, child's behaviour at home, parental academic expectations, child support from close friends, family structure and parenting. The pupils most at risk for developing SEBD would thus be male pupils attending schools where bullying is prevalent, who manifest behaviour difficulties at home, with low parental academic expectations and little support from close friends. They are pupils coming from single-parent families with high levels of parental stress and low levels of parental supervision. They have low self-efficacy, poor engagement in academic activities, poor communication skills, and poor relationship with the teacher and with the parents. They do not participate in local organisations. 
Table 2: Logistic Regression Analysis Using Parents’ Evaluations

\begin{tabular}{lcccc}
\hline & \multicolumn{3}{c}{ Parents' Evaluation } & \\
\hline Predictor & Chi square & P-value & Odds ratio & $95 \%$ Conf. Int. \\
\hline Gender & 7.879 & 0.005 & 3.986 & $(2.039-7.794)$ \\
Bullying & 9.421 & 0.009 & 3.648 & $(1.833-7.257)$ \\
Behaviour at home & 8.857 & 0.012 & 3.351 & $(1.789-6.273)$ \\
Parent academic expectation & 8.270 & 0.016 & 3.029 & $(1.689-5.431)$ \\
Support from close friends & 7.927 & 0.019 & 2.945 & $(1.601-5.417)$ \\
Family structure & 5.168 & 0.023 & 2.846 & $(1.628-4.976)$ \\
Parenting stress & 7.459 & 0.024 & 2.761 & $(1.534-4.973)$ \\
Pupils' participation in lessons & 7.224 & 0.027 & 2.598 & $(1.455-4.642)$ \\
Teacher-reported self-efficacy & 6.763 & 0.034 & 2.234 & $(1.205-4.143)$ \\
Teacher-reported engagement & 6.705 & 0.035 & 2.169 & $(1.245-3.776)$ \\
Communication skills & 6.540 & 0.038 & 1.963 & $(1.140-3.377)$ \\
Pupil-teacher relationship & 6.438 & 0.040 & 1.789 & $(1.022-3.135)$ \\
Participation in organisations & 6.340 & 0.042 & 1.726 & $(1.017-2.931)$ \\
Communication with parents & 6.202 & 0.045 & 1.684 & $(1.017-2.786)$ \\
Parenting supervision & 3.875 & 0.049 & 1.570 & $(1.000-2.464)$ \\
\hline
\end{tabular}

According to parents, males are 3.986 times more likely to exhibit SEBD than females. Pupils who are bullied experience SEBD 3.648 times more often than pupils who are not bullied. Pupils who misbehave at home are 3.351 times more likely to exhibit SEBD than peers who behave well. Students whose parents have low academic expectations of their children experience SEBD 3.029 times more often than peers whose parents have high academic expectations. Pupils who do not receive support from close friends are 2.945 times more likely to exhibit SEBD than peers who receive support. Pupils living in a single parent family structure exhibit SEBD 2.846 times more often than pupils living in a two-parent family structure. Pupils living in families with high levels of parenting stress are 2.761 times more likely to exhibit SEBD than peers experiencing low levels of parenting stress. Students who do not participate during lessons experience SEBD 2.598 times more often than peers who participate regularly. Pupils with low self-efficacy exhibit SEBD 2.234 times more often than peers with high self-efficacy. Students who do not actively engage in the learning process are 2.169 times more likely to experience SEBD than peers with high engagement. Pupils with poor communication skills exhibit SEBD 1.963 times more often than peers having good communication skills. Students with poor relationship with their teachers are 1.789 times more likely to exhibit SEBD than pupils who have good relationships. Pupils who do not participate in local organisations develop SEBD 1.726 times more often than more active peers. Students who have poor communication with parents exhibit SEBD 1.684 times more often than peers having good communication. Pupils with poor parenting supervision are 1.57 times more likely to experience SEBD than well supervised children.

\section{Discussion and Conclusion}

Poor relationships and adverse home and school climates stand out as significant contributors to social, emotional and behavioural difficulties. A longitudinal increase in SEBD is more likely to occur if a pupil has poor communication, poor self-esteem and self-efficacy, poor relationships with teacher and peers, poor behaviour at school, poor academic progress, has no friends, does not engage in classroom activities and does not participate in local organisations. Moreover, the pupil comes from a single parent family, with high levels of parenting stress, lack of supervision and family time and is often bullied by peers. Poor home-school communication and low parental academic expectations also contribute significantly to social, emotional and behavioural problems. Teachers and parents have similar views regarding factors that influence change in social, emotional and behaviour difficulties. Gender was the sole exception where teachers perceive females and parents perceive males to be more at risk for developing SEBD.

These are the students who are most at risk for developing SEBD unless the situations at home and at school do not change as the students move from one year to the other in primary school. The more risk factors they have, the more likelihood of difficulties in their social and emotional development, psychological wellbeing and academic achievement. The findings of the study clearly underline two main issues for intervention. First, in line with the biopsychosocial perspective described earlier, the study shows the multifacetedness and complexity of SEBD, and how various individual, peer, school and home factors influence SEBD in the first years of primary school. 
Prevention efforts need to focus particularly on the home and classroom systems, and seek to create strong and supportive communities based on caring and collaborative relationships, sense of competence and efficacy, good communication skills, and high expectations for all children. Children at risk would also need to have their needs adequately addressed as early as possible with collaboration between school, home and the community (National Institute for Health and Clinical Excellence, 2008; Weare and Nind, 2011). The study underlines the need for timely and effective intervention as early as possible, and to tackle any academic, engagement, relational and behaviour problems from the very beginning of school life. This would ensure that children's developmental trajectory would be redirected to healthy pathways when it is still possible to do so. The literature shows that interventions to prevent and remedy SEBD are more likely to be successful if they start as early as possible in children's life, and that healthy social and emotional development in the early years is linked to academic learning and social and emotional learning later on in childhood and adolescence (Domitrovich, Cortes and Greenberg, 2007; National Institute for Health and Clinical Excellence, 2008; Denham, Brown, and Domitrovich, 2010). The foundations for mental health difficulties, delinquency, criminality, social exclusion, relationship problems and substance abuse in adulthood are in most instances laid in childhood. Conversely the foundations for mental health and wellbeing are similarly laid in the early years, particularly in the creation of supportive, healthy and nurturing communities, such as the family, the peer group, the school, and the community (cf. Fergusson, Horwood, and Ridder, 2005).

This study was a relatively small scale study in one particular cultural context, and care must be taken in generalizing the findings to other contexts without consideration to the nature of such contexts. The study focused only on risk factors for SEBD, but it would be useful to identify the protective factors for SEBD as well, making use of a similar longitudinal design, and examine the interaction of risk and protective factors in the development and prevention of SEBD (Hawkins et al, 2002).

\section{References}

Aitkin, M., Anderson, D., Francis, B., \& Hinde, J. (1994). Statistical Models in GLIM. Oxford Science Publications.

Avramidis, E., \& Norwich, B. (2002). Teachers' attitudes towards integration/inclusion: a review of the literature. European Journal of Special Needs Education, 17(2), 129-149. http://dx.doi.org/10.1080/08856250210129056

Cefai, C., \& Cooper, P. (2010). Students without voices: the unheard accounts of secondary school students with social, emotional and behaviour difficulties. European Journal of Special Needs Education, 25(2), 183-198. http://dx.doi.org/10.1080/08856251003658702

Cefai, C., Cooper, P., \& Camilleri, L. (2008). Engagement Time: a national study of students with social, emotional and behaviour difficulties in Maltese schools. Malta: European Centre for Education Resilience and Socio-Emotional Health, University of Malta.

Centre for Disease Control and Prevention (2013). Mental Health Surveillance among Children- United States 2005-2011.

Cole, T., Daniels, H., \& Visser, J., (2005). The mental health needs of pupils with EBD. In R. Williams and M. Kerfoot (Eds) Child and Adolescent Mental Health Services. Oxford: Oxford University Press.

Colman, I., Murray, J., Abbott, R.A., Maughan, B., Kuh, D., Croudace, T.J., \& Jones, P.B. (2009). Outcomes of conduct problems in adolescence: 40 year follow-up of national cohort. British Medical Journal, 338, 208-211. http://dx.doi.org/10.1136/bmj.a2981

Cooper, P., \& Jacobs, B. (2011). From Inclusion to Engagement. Chichester: Wiley.

Denham, S. A., Brown, C., \& Domitrovich, C. E. (2010). "Plays nice with others": Social-emotional learning and academic success. Early Education and Development, 21, 652-680. http://dx.doi.org/10.1080/10409289.2010.497450

Dobson, A.J. (2001). An Introduction to Generalized Linear Models. Chapman \& Hall Publication, (2 ${ }^{\text {nd }}$ Edition). http://dx.doi.org/10.1201/9781420057683

Domitrovich, C. E., Cortes, R. C., \& Greenberg, M. T (2007). Improving Young Children's Social and Emotional Competence: A Randomized Trial of the Preschool "PATHS" Curriculum. Journal of Primary Prevention, 28(2), 67-91. http://dx.doi.org/10.1007/s10935-007-0081-0

Engle, P.L., \& Black. M.M. (2008). The effect of poverty on child development and educational outcomes. Annual NY Academic Science, 1136, 243-56. http://dx.doi.org/10.1196/annals.1425.023 
Fergusson, D.M., Horwood, L.J., \& Ridder, E.M. (2005). Show me the child at seven: the consequences of conduct problems in childhood for psychosocial functioning in adulthood. Journal of Child Psychology and Psychiatry, 46, 837-49. http://dx.doi.org/10.1111/j.1469-7610.2004.00387.x

Fletcher-Campbell, F., \& Wilkin, A. (2003). Review of the research literature on educational interventions for pupils with emotional and behavioural difficulties. Slough, UK: National Foundation for Educational Research.

Ford, T., Collishaw, S., Meltzer, H., \& Goodman, R. (2007). A prospective study of childhood psychopathology: independent predictors of change over three years. Social Psychiatry and Psychiatric Epidemiology, 42(12), 953-61. http://dx.doi.org/10.1007/s00127-007-0272-2

Gilligan, R. (2001). Promoting positive outcomes for children in need: the assessment of protective factors. In J. Horwath (ed.) The Child's World: assessing children in need. London: Jessica Kingsley Publishers.

Goodman, R. (1997). The Strengths and Difficulties Questionnaire: A Research Note. Journal of Child Psychology and Psychiatry, 38, 581-586. http://dx.doi.org/10.1111/j.1469-7610.1997.tb01545.x

Goodman, R., Renfrew, D., \& Mullick, M. (2000). Predicting type of psychiatric disorder from Strengths and Difficulties Questionnaire (SDQ) scores in child mental health clinics in London and Dhaka. European Child Adolescent Psychiatry, 9, 129-134. http://dx.doi.org/10.1007/s007870050008

Hawkins, J. D., Catalano, R. F., \& Arthur, M. W. (2002). Promoting science-based prevention in communities. Addictive Behaviors, 27(6), 951-976. http://dx.doi.org/10.1016/S0306-4603(02)00298-8

Kalambouka, A., Farrell, P., Dyson, A., \& Kaplan, I. (2007). The impact of placing pupils with special educational needs in main stream schools on the achievements of their peers. Educational Research, 39, 365-382. http://dx.doi.org/10.1080/00131880701717222

Linnenbrink, E.A., \& Pintrich, P.R. (2003). The role of self-efficacy in student engagement and learning in the classroom. Reading and Writing Quarterly: Overcoming Learning Difficulties, 19(2), 119-137. http://dx.doi.org/10.1080/10573560308223

MacBeath, J. (2006). Finding a voice, finding self. Educational Review, 58(2), 195-207. http://dx.doi.org/10.1080/00131910600584140

Maes, L., \& Lievens, J. (2003). Can school make a difference? A multilevel analysis of adolescent risk and health behaviour. Social Science and Medicine, 56, 517-29. http://dx.doi.org/10.1016/S0277-9536(02)00052-7

McCullagh, P., \& Nelder, J.A. (1983). Generalized Linear Models ( $1^{\text {st }}$ Edition). Chapman \& Hall Publication.

McLanahan, S. (2009). Fragile families and the reproduction of poverty. Annual American Academy of Political and Social Sciences, 62, 111-31. http://dx.doi.org/10.1177/0002716208324862

Nelder, J.A., \& Wedderburn, R.W.M. (1972). Generalized Linear Models. Journal of the Royal Statistical Society, A(135), 370-384.

O’Regan, F (2011). Exclusion from School and ADHD. International Journal of Emotional Education, 2(2), 3-18.

OECD (2009) Teaching and Learning International Survey (TALIS) [Electronic Version]. Last retrieved on $1^{\text {st }}$ October 2011 from www.oecd.org/edu/talis/firstresults

Parsons, C., Hayden, C., Godfrey, R. Howlett, K., \& Martin, T. (2001). Excluding Primary School Children - the Outcomes Six Years On. Pastoral Care in Education, 19(4), 4-15. http://dx.doi.org/10.1111/1468-0122.00206

Resnick, M.D., Bearman, P.S., \& Blum, R.W., et al. (1997). Protecting adolescents from harm. Findings from the National Longitudinal Study on Adolescent Health. The Journal of the American Medical Association, 278(10), 823-832. http://dx.doi.org/10.1001/jama.1997.03550100049038

Rose, W., Aldgate, A., McIntosh, M., \& Hunter, H. (2009). High-risk children with challenging behaviour: changing directions for them and their families. Child and Family Social Work, 14, 178-188. http://dx.doi.org/10.1111/j.1365-2206.2009.00622.x

Siqueira, L.M., \& Diaz, A. (2004). Fostering resilience in adolescent females. Mount Sinai Journal of Medicine, 71(3), 148-53.

Weare, K., \& Nind, M. (2011). Promoting Mental Health of children and adolescents through schools and school-based interventions. Southampton: University of Southampton. 